\title{
Environmental bioremediation
}

\section{Opinion}

Bioremediation means using a biological remedy to reduce or clean up contamination. This makes it different from remedies where contaminated soil or water is removed for chemical treatment or decontamination, incineration or burial in a landfill. Microbes are often used to address environmental problems encountered in soil, water and sediment. Plants have also been used to facilitate bioremediation processes. This is known as phytoremediation. Biological processes have been used for certain inorganic materials, such as metals to reduce radioactivity and to correct organic contaminants. In the case of metal contamination, the usual challenge is to accumulate metal in parts of the crop, which must then be disposed of in a hazardous landfill before or after incineration to reduce the ash plant. Two exceptions are mercury and selenium, which can be released as volatile elements directly from plants to the atmosphere. The concept and practice of using plants and micro-organisms to repair contaminated soils has developed over the last thirty years. The idea of bioremediation became popular with the beginning of the twenty-first century. In principle, genetically modified plants and microorganisms can greatly improve the potential range of bioremediation. For example, bacterial enzymes handled in plants can accelerate the decomposition of TNT and other explosives. With transgenic poplars bearing a bacterial gene, methyl mercury can be converted to elemental mercury, which is released into the atmosphere at extreme dilution. However, concerns about the release of these organisms into the environment have limited actual applications on the ground. Natural bioremediation has occurred for millions of years. The biodegradation of dead vegetation and dead animals is a kind of bioremediation. It is a natural part of the cycles of carbon, nitrogen and sulfur. The chemical energy present in waste is used by microorganisms to grow as they convert organic carbon and hydrogen into carbon dioxide and water.

When bioremediation is applied by people, it is said that processes of microbial biodegradation are managed. However, bioremediation occurs naturally and often occurs before efforts to manage the process. One of the first examples of managed bioremediation was landbased agriculture (refers to the managed biodegradation of organic compounds that are distributed on the soil surface, fertilized and then plowed). Many oil companies have used it. Organic compounds of high molecular weight (i.e. sludge and oil waste) are spread on the soil and then seeded into the soil with fertilizers as part of the process of bioremediation. Good conditions for microbial biodegradation are maintained by controlling soil moisture and soil nutrients. In 1974, Raymond received a patent for the bioremediation of gasoline. This is one of the first patents granted for a bioremediation process. Composting has been used as a bioremediation process for many different organic compounds. It is widely used to recycle nutrients in garden and garden waste. Finished compost can be used as a soil conditioner. Extending composting technology to new bioremediation applications requires experiments. The process of biodegradation must be effective in the context of existing environmental conditions and the odors and gases generated by the process must be strictly controlled. In situ processes (degradation of contaminants in place)
Volume 2 Issue 2 - 2017

\author{
Hiral Borasiya, Maulin P Shah \\ Division of Applied \& Environmental Microbiology, Enviro \\ Technology Limited, India
}
Correspondence: Maulin P Shah, Industrial Waste Water Research Laboratory, Division of Applied \& Environmental Microbiology, Enviro Technology Limited, India, Emailshahmp@beil.co.in

Received: February 02, 2017| Published: February 09, 2017

are often recommended because less material needs to be moved. These processes can be designed with or without plants. The plants were used because they absorb large amounts of water. This helps to control contaminated water, such as a plume contaminating groundwater, in the soil. Aerobic processes (using oxygen) can occur in the unsaturated soil layer. The oxygen moves in the unsaturated zone by diffusion through the pores into the soil. Some plants also provide ways to move oxygen into the soil. This can be very important in increasing the aerobic degradation of organic compounds.

Petroleum contaminated soil was remediated in situ with added plants to improve degradation processes. Microbial biodegradation of resorcinol, toluene, aromatic compounds, oil, gasoline, jet fuel and other petroleum hydrocarbons occurs in the soil. When plants are present, soil erosion is reduced and more microbes are present in the root zone of the plant. Methyl tertiary butyl ether used in gasoline to improve the octane rating of fuel, is difficult to eliminate because it is very soluble in water and difficult to decompose using microbes normally present in floor. In plant bioremediation, MTBE is moved from the soil to the atmosphere with water that plants absorb from the soil and release into the air. MTBE decomposes rapidly into the atmosphere. Benzotriazoles used as corrosion inhibitors in antifreeze de-icing fluids and airplanes, are treated by plant bioremediation. Benzotriazole adsorbs or sticks to the roots of the plant and ends up being part of the plant biomass. Trichlorethylene is a common chlorinated solvent that is bio transformed in soil. It can be taken by plants with water. Then the TCE diffuses into the atmosphere where it is destroyed by atmospheric processes. Biodegradation requires good nutritional and environmental conditions for biodegradation. When oxygen is needed for the oxidation of organic contaminants, bio venting (pumping air into the soil) is often used. Sometimes fertilizer is added to the soil. In some places, irrigation is necessary for plants or microbes to develop.

\section{Acknowledgements}

None.

\section{Conflict of interest}

The author declares no conflict of interest. 